\title{
Facile Synthesis of Zinc Oxide Nanoparticles with Antibacterial, Humidity Sensing and Photocatalytic Behaviour
}

\author{
R. Renukadevi And R. Sundaram* \\ $P G$ and Research Department of Chemistry, Presidency College (Autonomous), \\ Chennai - 600 005, Tamilnadu, India. \\ *Corresponding author: drsundarampresidency@gmail.com
}

\begin{abstract}
Synthesis of zinc oxide $(\mathrm{ZnO})$ nanoparticles was carried out by simple co-precipitation technique. The synthesized $\mathrm{ZnO}$ nanoparticles were characterized by powder X-Ray Diffraction (XRD) for phase analysis, Scanning electron microscopy (SEM) for morphology, Dynamic light scattering (DLS) for particle size analysis, Ultra-violet absorption spectra for optical properties. The antibacterial activity of the synthesized ZnO nanoparticles was assessed against both the gram-positive and gram-negative bacterial strains. Staphylococcus aureus and Escherichia coli were test pathogens under study that were tested for its bacterial growth against synthesized $\mathrm{ZnO}$ nanoparticles. The $\mathrm{ZnO}$ nanoparticles shows prominent zone of inhibition towards growth of bacteria's. The humidity sensing capability of synthesized $\mathrm{ZnO}$ nanoparticles was analyzed at different relative humidity ranges. It exhibits the sensitivity factor of 922 with quick response and recovery characteristics. The photocatalytic ability was analyzed using synthesized $\mathrm{ZnO}$ nanoparticles as photocatalyst for the degradation of an organic dye - Rhodamine B (Rh B) under visible light source. The degradation efficiency was above $98 \%$ within 45 minutes of irradiation, this proves the stupendous degradation of the $\mathrm{Rh} B$ dye solution.
\end{abstract}

Keywords: ZnO nanoparticles, Antibacterial activity, Humidity sensor and Photocatalyst.

\section{INTRODUCTION}

In the modern era, nanotechnology grasps the attention; as it paves way to the modern innovations in the field of science and technology. Nanotechnology dealing with particle size in nanometer range finds application in the environmental, sensing, medical, optical, communication and electromagnetic fields. The various synthesis techniques of these nanoparticles greatly influence in its size, morphology and applications. Among the nanoparticles, the metal oxides were known to possess exorbitant physicochemical properties and finds plausible applications in various sectors. Among the metal oxides, Zinc oxide $(\mathrm{ZnO})$ was remarkable due to its astounding properties. $\mathrm{ZnO}$, an n-type semiconductor with wider band gap were found to be useful in several applications in the field of sensors, medical, optical, solar cells, photocatalysis and electromagnetic areas. There were various techniques of the synthesis of the $\mathrm{ZnO}$ nanoparticles such as sol-gel, hydrothermal, microwave assisted method, co-precipitation, solid state reaction. Amongst which the eco-friendly, economic, simple and user-friendly approach was the requisite characteristics for its efficient application in various sectors. The zinc oxide leads to its plentiful applications; widely in electrical and biological sectors [1-4]. The urbanized world with modern amenities was in an urge to focus on medical field; as the infectious diseases caused by multidrug resistant microorganisms were the serious issue leading to several medical complications day-by-day. Bacterial infections were the serious issue; as it also affects the pleasant life of mankind by indirectly affecting the various processes in food, textile, medicine and several industries. $\mathrm{ZnO}$ nanoparticles possess the antibacterial properties against several gram-positive and gram-negative species. Nanoparticles have properties that differ from the bulk materials due to its surface-to-volume ratio, size and morphology. Among the different pathogens, antibiotic-resistant pathogens are the area of concentration as they are culpable for various intricate infectious diseases. Therefore, there arises a need for biologically active, antibacterial material against those multi-drug resistant bacteria's. The antibiotic-resistant, multidrug resistant (Staphylococcus aureus, Escherichia coli) pathogens are known to be more infectious as the infections and diseases caused by them are more complicated to cure [5-7]. Following the health sector, humidity monitoring, detection and control had been vital in wide areas as it possess many domestic applications as in intelligent control, 


\section{International Journal of Research in Advent Technology, Vol.7, No.1, January 2019 E-ISSN: 2321-9637 \\ Available online at www.ijrat.org}

cooking control and serves in medical sectors in sophisticated maintenance processes. Humidity monitoring also plays role in agriculture for maintaining and acquiring proper level of moisture for plant growth and humidity had inevitable position in food processing and many production processes. The existence of humidity sensing material of various types drags the focus towards miniaturization, fabrication and production of humidity sensors with low cost, user-friendly characteristics. Relative humidity sensors were the preferable and commonly used due to its economic and user-friendly characteristics. The surface of the sensing material and the water molecules shows surface related interaction such as adsorption mechanism, thus the sensing ability of the material was monitored by electrical measurements which were closely related to the changes in the relative humidity percentage. Several metal oxides and nanoparticles possess sensing behavior; but there remains the need for commercial grade sensor with the high sensitivity, low response time, high accuracy and low cost material [8-10]. Now-a-days, the water pollution had been the great threat to the society. The majority of contaminants, impurities in the water bodies were the dyes from industrial effluents. This contaminant not only affects the water table, but also leads to acute health issues and affecting both the aquatic as well as terrestrial lives. Among the various ways of treatment of the effluents, photocatalysis had been the solution for the removal of dye contamination from water, as it was cost effective and environmental friendly approach. Metal oxides, in particular semiconductor materials were known to be efficient in photocatalysis. $\mathrm{ZnO}$ have been known to possess the photocatalytic property and it was seemed to be environment-friendly, biocompatible material. The redox reactions of the photocatalysis process degrade the dyes without leaving any secondary pollutants to the environment [11-13].

Thus, the aim of the work was to synthesize material with multiple applications. In the present work - we synthesized multifunctional $\mathrm{ZnO}$ nanoparticles which were analyzed for its antibacterial activity, humidity sensing capability and photocatalytic studies.

\section{EXPERIMENTAL SECTION}

\section{1. Synthesis of $\mathrm{ZnO}$ nanoparticles}

$0.2 \mathrm{M}$ solution of sodium hydroxide and $0.1 \mathrm{M}$ solution of zinc nitrate were mixed and magnetically stirred for two hours. The precipitate obtained was washed several times and filtered; followed by the calcination of the precipitate in muffle furnace at $500^{\circ} \mathrm{C}$ for four hours. The calcined precipitate of $\mathrm{ZnO}$ nanoparticles were synthesized by template-free, surfactant-free technique.

\section{2. Characterization}

"XPERT-PRO" was used to study the powder XRD for phase analysis. Surface morphology was analyzed using AU Quanta 250 FEG scanning electron microscope, the particle size was measured using Zetasizer $3000 \mathrm{HS}$ instrument and the UVspectral studies were done using JASCO V-630 spectrophotometer.

\section{3. Antibacterial, humidity sensing and photocatalytic studies}

The antibacterial activity of the $\mathrm{ZnO}$ nanoparticles was assessed using agar well diffusion technique. The synthesized $\mathrm{ZnO}$ nanoparticles were taken with DMSO solvent. The DMSO also acts as control [14]. The synthesized $\mathrm{ZnO}$ nanoparticles were prepared into stock solution of $1 \mathrm{mg} / \mathrm{ml}$ concentration which was then diluted to $25 \mu \mathrm{l} / \mathrm{ml}, 50 \mu 1 / \mathrm{ml}, 75 \mu 1 / \mathrm{ml}$ and $100 \mu \mathrm{l} / \mathrm{ml}$. Gram-positive Staphylococcus aureus and gram-negative Escherichia coli were selected as test pathogens. The agar medium swabbed with pathogens was loaded with different concentrated solutions and control. All the tests were done in triplicates and the average zone of inhibition was noted which was used to predict the antibacterial activity of the synthesized $\mathrm{ZnO}$ nanoparticles.

Anhydrous phosphorus pentoxide; saturated solutions of potassium acetate, calcium chloride hexahydrate, zinc nitrate hexahydrate, calcium nitrate tetrahydrate, sodium nitrite, ammonium chloride, barium chloride dihydrate and copper sulphate petahydrate were placed in a closed apparatus which serves as controlled humidity arrangement with relative humidity $(\mathrm{RH})$ of $5 \%, 20 \%, 31 \%, 42 \%, 51 \%$, $66 \%, 79 \%, 88 \%$ and $98 \%$ respectively [15]. The synthesized $\mathrm{ZnO}$ nanoparticles were used as sensing element in the two-probe set-up, which was used to analyze the relative humidity. The $\mathrm{ZnO}$ nanoparticles infused two-probe sensing set-up was kept undisturbed for two hours. After the resting time, the sensitivity was measured using electrical measurement of DC resistance. The response and recovery time was also studied.

The photocatalytic activity of the synthesized $\mathrm{ZnO}$ nanoparticles was analyzed by 


\section{Available online at www.ijrat.org}

using $\mathrm{ZnO}$ nanoparticles as photocatalyst for the photodegradation of the organic dye - rhodamine $\mathrm{B}$ $(\mathrm{Rh}$ B) [16]. $0.025 \mathrm{~g}$ of the synthesized $\mathrm{ZnO}$ nanoparticles was taken to degrade $100 \mathrm{ml}$ of aqueous $\mathrm{Rh} \mathrm{B}$ solution of concentration $\left(2 \times 10^{-5} \mathrm{M}\right)$. The suspensions of photocatalyst and dye were stirred in dark for 30 minutes for attaining equilibrium; followed by which the suspensions were kept under 250W tungsten-halogen lamp as visible light source. After irradiation, the suspension collected at regular intervals was centrifuged and filtered. The supernatant liquid was subjected to UV-absorption studies to analyze the concentration of the Rh B dye.

\section{RESULTS AND DISCUSSION}

3. 1. Analyses on Phase, morphology, size and optical properties

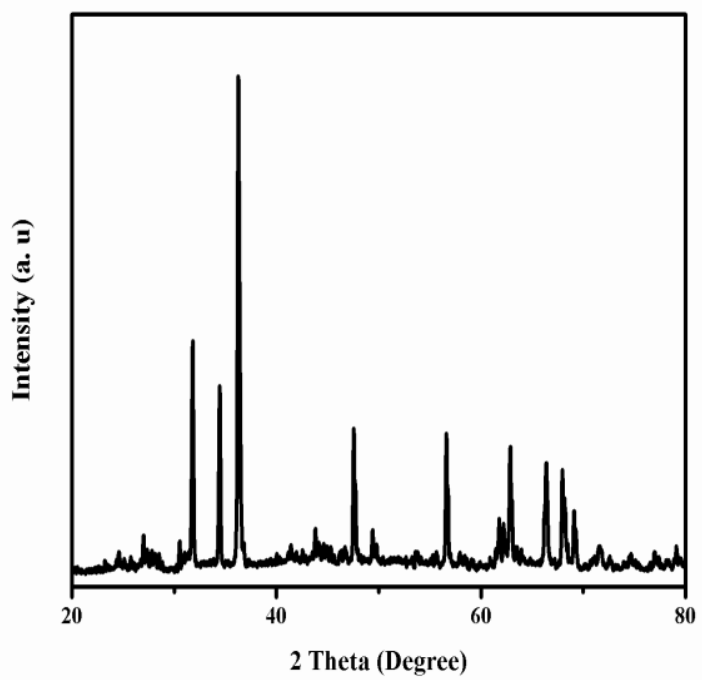

Fig. 1. Powder XRD of synthesized $\mathrm{ZnO}$ nanoparticles.

The powder XRD analysis of synthesized $\mathrm{ZnO}$ nanoparticles shows thorny diffraction peaks, which were found to be in accordance with JCPDS number: 89-0510. The Powder XRD pattern of synthesized $\mathrm{ZnO}$ nanoparticles recorded with $2 \theta$ values from 20 to 80 degrees was given in Fig. 1 . According to the JCPDS, the synthesized $\mathrm{ZnO}$ nanoparticles possesses primitive lattice with hexagonal system and cell parameters $\mathrm{a}=3.248 \mathrm{~A}^{\circ}, \mathrm{c}$ $=5.205 \mathrm{~A}^{\circ}$.

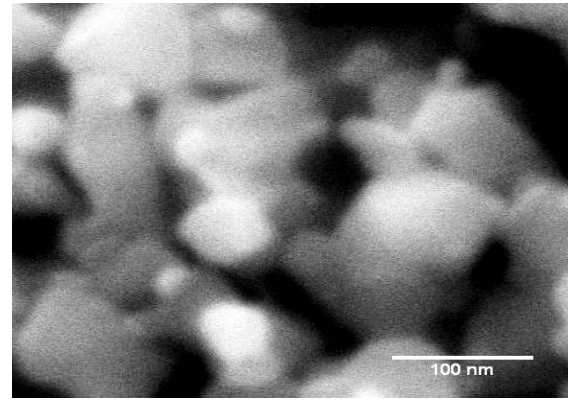

Fig. 2. SEM image of the synthesized $\mathrm{ZnO}$ nanoparticles

The SEM image of the synthesized $\mathrm{ZnO}$ nanoparticles was shown in Fig. 2. The SEM image shows irregular particles with uneven distribution and minor congregation. The template-free, surfactantfree synthesis procedure was reflected in this morphological behavior. Further, the particle size analysis using DLS shows the polydispersity of particles and the intensity percentage was greater between $30 \mathrm{~nm}$ to $90 \mathrm{~nm}$. The most intense peak was recorded at $56.3 \mathrm{~nm}$ as given in Fig. 3. This shows that the synthesized nanoparticles lie under the nanorange.

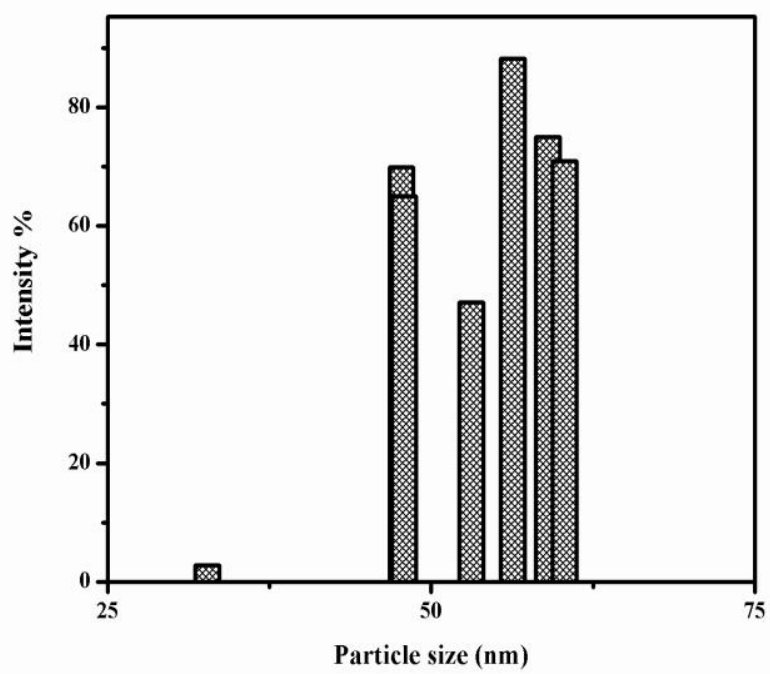

Fig. 3. Particle size analysis of $\mathrm{ZnO}$ nanoparticles

The optical property analyzed by UVabsorption spectra was shown in Fig. 4. The absorption edge was at $371 \mathrm{~nm}$ and the band gap value was calculated using the formula $\mathrm{Eg}=1240 / \lambda$, where $\lambda$ is the absorption edge [17]. The calculated 


\section{Available online at www.ijrat.org}

band gap value was $3.34 \mathrm{eV}$. This band gap facilitates electronic transitions, thereby increasing its potential towards applications as photocatalyst.

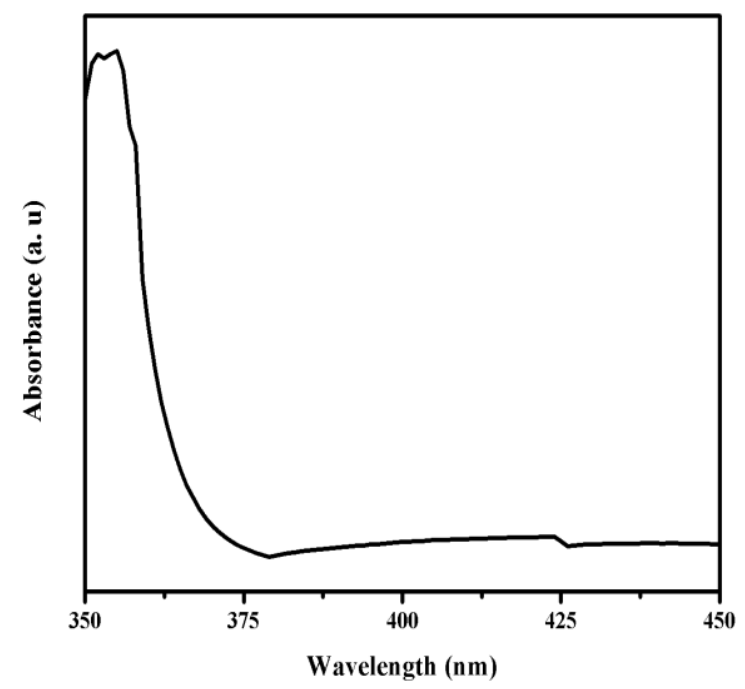

Fig. 4. UV-Absorption spectra of $\mathrm{ZnO}$ nanoparticles.

\section{2. Antibacterial activity of the synthesized ZnO nanoparticles}

The antibacterial activity of the synthesized $\mathrm{ZnO}$ nanoparticles assessed against gram-positive and gram-negative bacterial strains which shows prominent zone of inhibition. As there was no inhibition zone observed with DMSO solvent, the antibacterial activity possessed by the DMSO was nullified and the zone of inhibition was entirely due to the synthesized $\mathrm{ZnO}$ nanoparticles. The zone of inhibition measured after 24 hours of incubation of agar wells loaded with $\mathrm{ZnO}$ nanoparticles exhibits the satisfactory zone of inhibition even with minimal amount of concentration of the $\mathrm{ZnO}$ nanoparticles.

The antibacterial activity of the synthesized nanoparticles was given in Fig. 5. The antibacterial activity of the synthesized $\mathrm{ZnO}$ nanoparticles against each bacterial species increases with the increase in the concentration of the nanoparticles. However, the concentration of $\mathrm{ZnO}$ nanoparticles had an impact on the antibacterial assay. It exhibits the variation in the zone of inhibition for each concentration. There was the fluctuation in the highest inhibition zone between the staphylococcus aureus and Escherichia coli with respect to each concentration. The bacterial resistivity monitoring was continued for 36 hours to estimate the time depending bacterial resistivity character of the antibacterial agent. Once the zone of inhibition was measured after 24 hours, the time dependence bacterial resistivity was assessed by continuously keeping the petridish undisturbed for 36 hours.

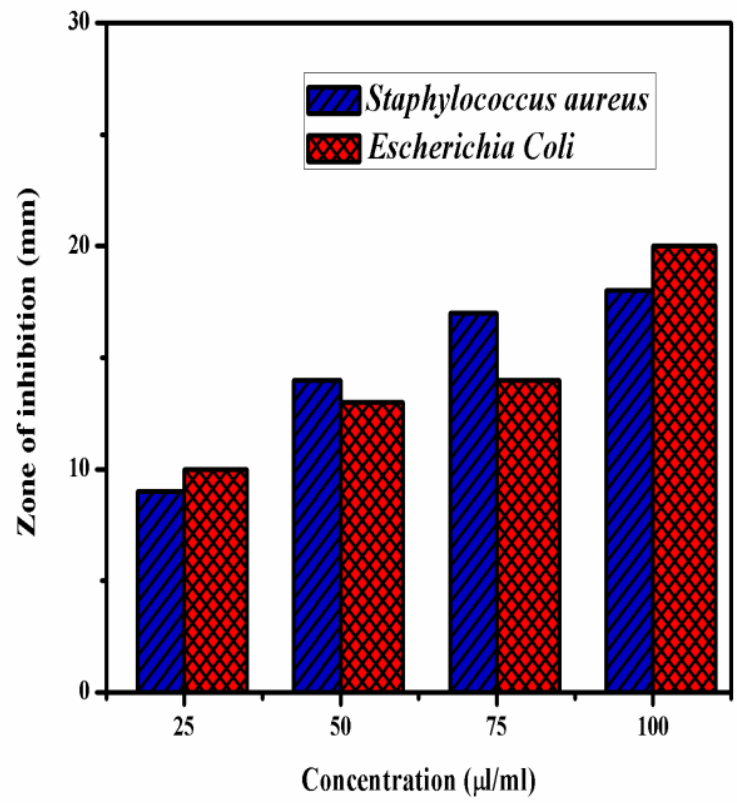

Fig. 5. Antibacterial assay of $\mathrm{ZnO}$ nanoparticles

As the time goes on increasing, the zone of inhibition decreases and there was decrease in the bacterial resistivity character of $\mathrm{ZnO}$ nanoparticles. The antibacterial activity assessed after 36 hours was given in Fig. 6. The bacterial resistivity of the $\mathrm{ZnO}$ nanoparticles was attributed to the biological mechanism involving at cellular level. The zone of inhibition varies due to the presence of thick layer of peptidoglycan in the gram-positive species; which was thin in gram-negative species. These are the characteristics responsible for difference in inhibition zone and interaction of nanoparticles at cellular level. The interaction of the synthesized $\mathrm{ZnO}$ nanoparticles with the bacterial cell followed by the reactions producing ROS were responsible to interlude the metabolism of the bacterial species. This mechanism would obviously result in impairment of bacterial cell, thereby causing cell damage and finally leads to the death of the bacteria $[18,19]$. 


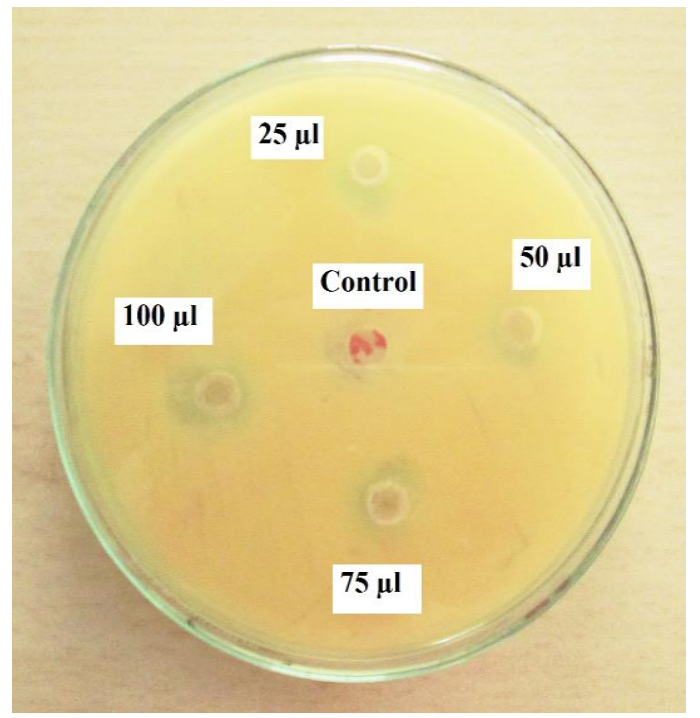

Fig. 6. Time dependent antibacterial assay after 36 hours.

\subsection{Humidity sensing behavior of $\mathrm{ZnO}$ nanoparticles}

The humidity sensor studies of the synthesized $\mathrm{ZnO}$ nanoparticles were examined in the relative humidity range of 5\% to $98 \%$. The respective resultant resistance values were large numerical integers represented in the ohm units. Thus, the graph was plotted against $\log \mathrm{R}$ versus $\mathrm{RH} \%$. The plot explains the sensitivity report on humidity sensing ability of $\mathrm{ZnO}$ nanoparticles; as the relative humidity increases, the $\log \mathrm{R}$ values drops consistently as shown in Fig. 7.

The sensitivity factor $\left(\mathrm{S}_{\mathrm{f}}\right)$ of the synthesized $\mathrm{ZnO}$ nanoparticles was calculated using the ratio of $\mathrm{R}_{5 \%} / \mathrm{R}_{98 \%}$, where $\mathrm{R}_{5 \%}$ and $\mathrm{R}_{98 \%}$ are the $\mathrm{DC}$ resistances at $5 \%$ and $98 \%$ of relative humidity respectively. The sensitivity factor of 922 shows the prominent humidity sensing ability of the $\mathrm{ZnO}$ nanoparticles.

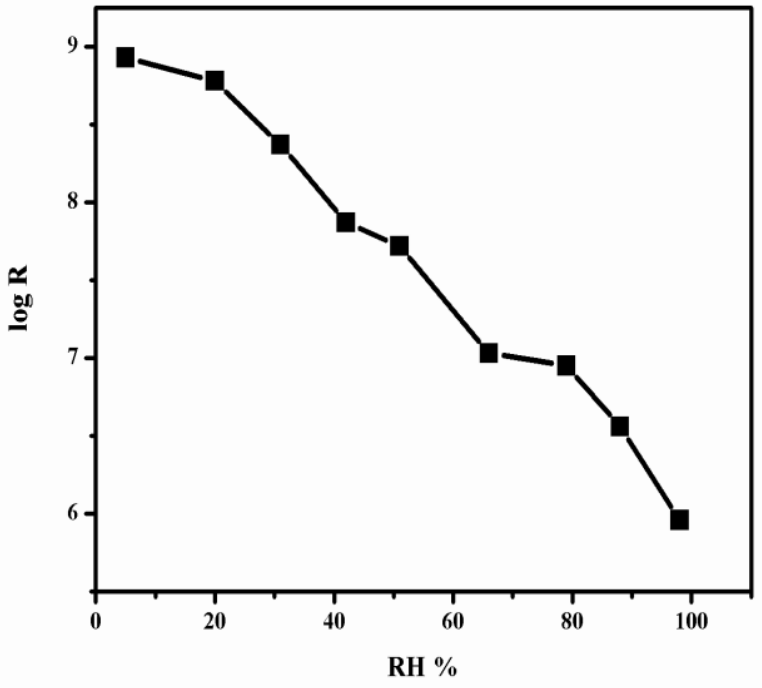

Fig. 7. Humidity sensing ability of $\mathrm{ZnO}$ nanoparticles

The mechanism of sensing behavior of the synthesized nanoparticles was attributed to the surface reactions. The adsorption of water molecules by the synthesized nanoparticles facilitates condensation through the microscopic pores between the nanoparticles. These surface changes were encountered by its impact and reflection in the changes of electrical measurements. However, the sensing ability and the mechanism of action were greatly influenced by the particle size, porosity, morphology and the synthesis technique [20]. The response and recovery characteristic of the synthesized $\mathrm{ZnO}$ nanoparticles towards humidity sensing nature was analyzed by varying the $\mathrm{RH} \%$ from 5\% to $98 \%$. The response and recovery characteristic graph was shown in Fig. 8. As the quick response and recovery characteristic was a necessary criterion for better sensing material; the synthesized $\mathrm{ZnO}$ nanoparticles show response at $30 \mathrm{~s}$ and recovery at $100 \mathrm{~s}$. This also evident the adsorption and desorption ability of the synthesized $\mathrm{ZnO}$ nanoparticles. The quick response and recovery characteristic of the synthesized zinc oxide nanoparticles makes it applicable in commercial grade. 


\section{Available online at www.ijrat.org}

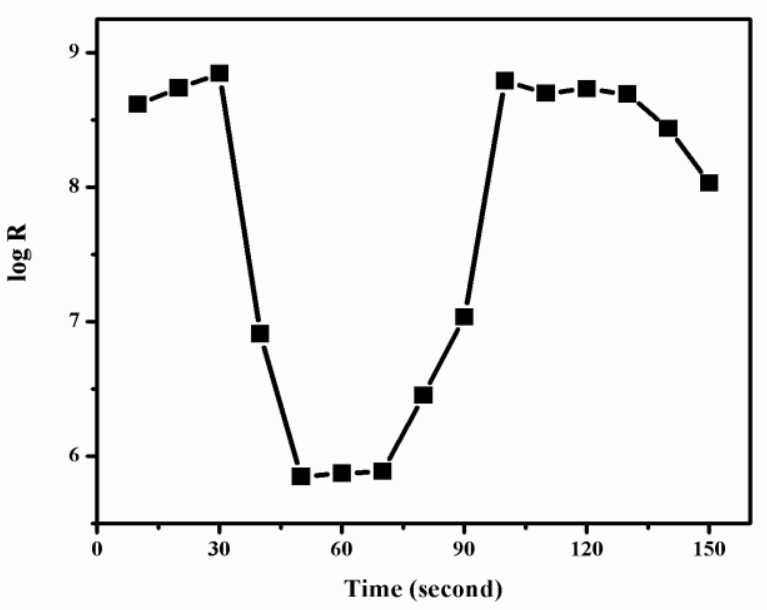

Fig. 8. Response and recovery characteristic of $\mathrm{ZnO}$ nanoparticles

\section{4. Photocatalytic activity}

The photocatalytic activity of the synthesized $\mathrm{ZnO}$ nanoparticles against $\mathrm{Rh} \mathrm{B}$ dye were demonstrated under visible light and the photodegradation of $\mathrm{Rh} B$ were clearly observed from the UV-absorption plot in Fig. 9.

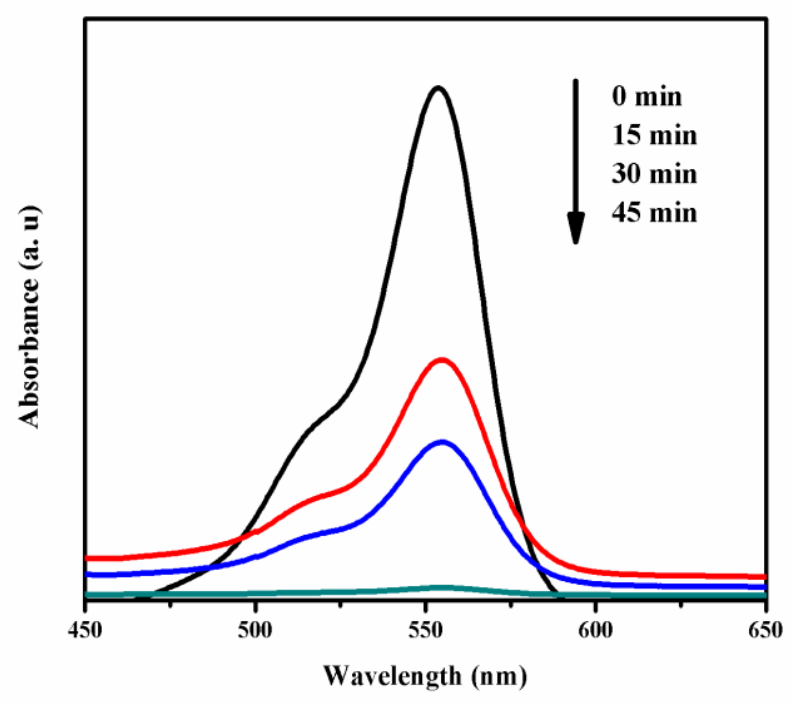

Fig. 9. Photocatalytic activity of $\mathrm{ZnO}$ nanoparticles towards $\mathrm{Rh} \mathrm{B}$ degradation.

The concentration of the dye was observed to decrease with increase in irradiation time. The color of the Rh B dye slowly pales and become lighter from initial time to 45 minutes of irradiation.
The diminishing of dark pink to pale color was clearly visible from the solution obtained at regular time intervals. The solutions obtained at regular intervals were displayed in Fig. 10 exhibiting Rh B solution from 0 minutes to 60 minutes. The sample bottle at position- 5 , shows the $\mathrm{Rh} \mathrm{B}$ at 60 minutes. There was no remarkable change noticed at the concentration of the Rh B dye between 45 and 60 minutes. Thus, minimum time of 45 minutes at that respective concentration of nearly zero was considered as the time for maximum degradation of the $\mathrm{Rh} \mathrm{B}$ dye solution. The plot of $\mathrm{C} / \mathrm{C}_{0}$ versus time was given in Fig. 11. This explains that the Rh $\mathrm{B}$ was not photodegraded automatically in the absence of any photocatalytic material. The degradation in the absence of synthesized photocatalyst was not eminent. But, the degradation in the presence of $\mathrm{ZnO}$ nanoparticles shows decrease in the concentration of the $\mathrm{Rh} \mathrm{B}$ with increase in time. The degradation efficiency was calculated using the formula,

$$
\text { Degradation efficiency }=\left[\left(\mathrm{A}_{0}-\mathrm{A}\right) / \mathrm{A}_{0}\right] \times 100
$$

Where, $\mathrm{A}_{0}$ is the initial concentration of the $\mathrm{Rh} \mathrm{B}$ dye and $\mathrm{A}$ is the concentration of the $\mathrm{Rh} \mathrm{B}$ dye after 45 minutes [21].

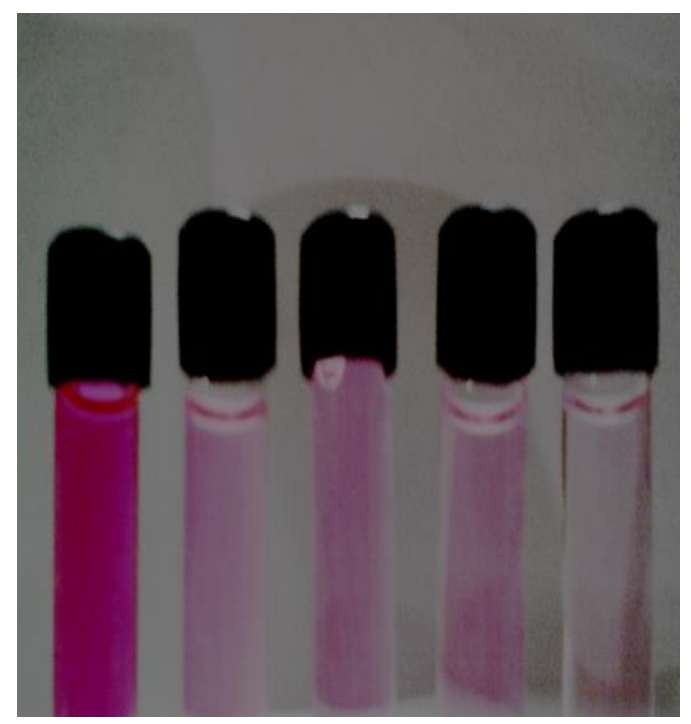

Fig. 10. Color of Rh B dye solution during degradation process.

The degradation efficiency after 45 minutes was found to be $98.54 \%$ and the concentration was reduced to approximately zero. The degradation by the synthesized $\mathrm{ZnO}$ photocatalyst was overwhelming and the mechanism/processes in the 
degradation of $\mathrm{Rh} B$ were significantly via the decomposition of conjugated ring system in $\mathrm{Rh} \mathrm{B}$ molecule. As there was no significant hypsochromic shift; the de-ethylation would not be the dominant process in the photodegradation reaction. Thus, the adsorption of the nanoparticles on the $\mathrm{Rh} \mathrm{B}$ dye molecules; thereby facilitates the redox reactions producing free radical species followed by its attack towards the decomposition of conjugated chromophores were concluded to be the steps mainly involving in the photodegradation of the $\mathrm{Rh} \mathrm{B}$ dye $[22,23]$.

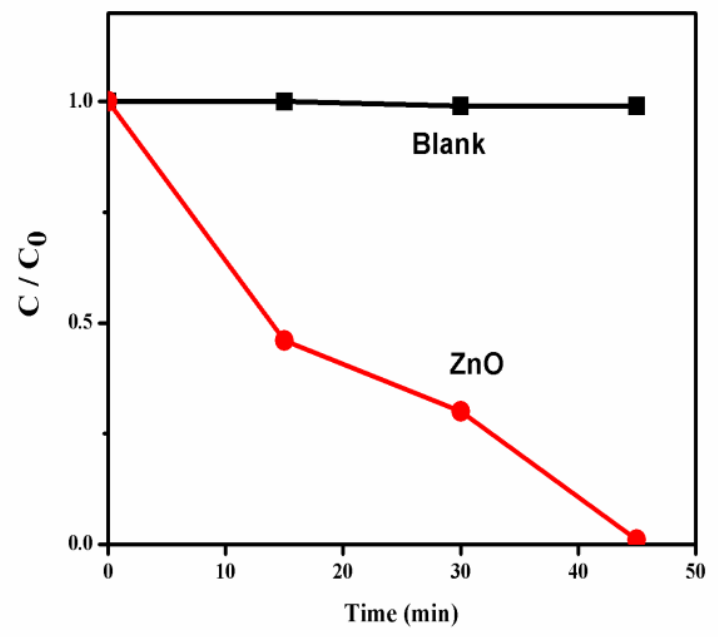

Fig. 11. Photodegradation - with $\mathrm{ZnO}$ and without $\mathrm{ZnO}$ nanoparticles.

\section{CONCLUSION}

The synthesized $\mathrm{ZnO}$ nanoparticles are known to possess hexagonal system in accordance with JCPDS number. The morphology of the $\mathrm{ZnO}$ nanoparticles shows irregular distribution of particles with small huddles and porosity thereby facilitating its application oriented properties. The particle size analysis of the synthesized $\mathrm{ZnO}$ nanoparticles shows particles with high intensity and maximum number of particles focused in the range of $56 \mathrm{~nm}$. The band gap of $3.34 \mathrm{eV}$ favors the potential of the nanoparticles towards its applications. The bacterial resistivity of the synthesized $\mathrm{ZnO}$ nanoparticles against the grampositive (Staphylococcus aureus) and gram-negative (Escherichia coli) species was observed. The maximum zone of inhibition was against gramnegative (Escherichia coli) species with maximum concentration of $\mathrm{ZnO}$ nanoparticles. The humidity sensing behavior of the synthesized $\mathrm{ZnO}$ nanoparticles possesses sensitivity factor of 922 with fast response and recovery time period of $30 \mathrm{~s}$ and $100 \mathrm{~s}$ respectively. The relation between relative humidity and electrical measurements (resistivity) were exhibited by the decrease in $\log \mathrm{R}$ (changes in the electrical measurements) with increase in RH\%. The stupendous sensitivity factor of 922 makes the synthesized $\mathrm{ZnO}$ nanoparticles as an efficient humidity sensing material. The photocatalytic degradation of $\mathrm{Rh} \mathrm{B}$ by the synthesized $\mathrm{ZnO}$ nanoparticles shows degradation efficiency of 98.54\% within 45 minutes of irradiation which was significant, as it proves the photodegrading ability of the organic dye $-\mathrm{Rh} \mathrm{B}$. Thus, the synthesized $\mathrm{ZnO}$ nanoparticles can be known as multi-functional material as these nanoparticles were efficient with antibacterial, humidity sensing and photocatalytic applications.

Based on these antibacterial, humidity sensing and photocatalytic properties, the synthesized $\mathrm{ZnO}$ nanoparticles can be used in future; to be applicable in the variety of fields for numerous applications such as antibiotics, humidity sensor and in wastewater treatment.

\section{Acknowledgement}

The authors are thankful to Directorate of Collegiate Education, Tamilnadu Government Higher Education and Government of Tamilnadu for funding - "state government research scholarship" for the scholar to perform the research work with reference of $49500 / \mathrm{K} 2 / 2015$.

\section{REFERENCES}

[1] A. Singh, B. Gaud, H. Narayan, R. Kurkure and S. Jaybhaye, "Eco-friendly synthesis of zinc oxide nanoparticles for rayon pulp", International science, Technology \& innovation conference \& Expo, National university of Lesotho, Maseru, Lesotho, January 23-25, 2018.

[2] O. E. Onoghwarite and O. P. Ikechukwu, "Emerging trends in nanoabsorbents absorption applications", International journal of advances in scientific research and engineering (ijasre), vol. 4(11), 2018.

[3] S. Shahid, S. A. Khan, W. Ahmad, U. Fatima and S. Knawal, "Size-dependent bacterial growth inhibition and antibacterial activity of Ag-doped $\mathrm{ZnO}$ nanoparticles under different atmospheric conditions", Indian Journal of Pharmaceutical Sciences, vol. 80(1), pp. 173-180, 2018. 
International Journal of Research in Advent Technology, Vol.7, No.1, January 2019

E-ISSN: 2321-9637

Available online at www.ijrat.org

[4] N. V. Kaneva and C. D. Dushkin, "Preparation of nanocrystalline thin films of $\mathrm{ZnO}$ by sol-gel dip coating", Bulgarian chemical communications, vol. 43(2), pp. 259-263, 2011.

[5] J. T. Seil and T. J. Webster, "Antimicrobial applications of nanotechnology: methods and literature", International journal of nanomedicine, vol. 7, pp. 2767-2781, 2012.

[6] S. K. R. Namasivayam, M. Prasanna and S. Subathra, "Synergistic antibacterial activity of zinc oxide nanoparticles with antibiotics against the human pathogenic bacteria", Journal of chemical and pharmaceutical research, vol. 7(3), pp. 133-138, 2015.

[7] A. M. Diez-Pascual, "Antibacterial activity of nanomaterials", Nanomaterials, vol. 8(359), 2018.

[8] L. Chitra, S. Srinivasan and B. Praveen kumar, "Characterization of composite metal oxide humidity sensor for oil lubricating system-A review", International journal of pure and applied mathematics, vol. 118(5), pp. 815-823, 2018.

[9] T. Thiwawong, K. Onlaor, N. Chaithanatkun and B. Tunhoo, "Preparation of copper doped zinc oxide nanoparticles by precipitation process for humidity sensing device", International conference on science and technology of emerging materials, AIP Conf. Proc., 2010.

[10] V. Jeseentharani, B. Jeyaraj, J. Pragasam, A. Dayalan and K. S. Nagaraja, "Humidity sensing properties of $\mathrm{CuO}, \mathrm{ZnO}$ and $\mathrm{NiO}$ composites", Sensors \& Transducers journal, vol. 113(2), pp. 48-55, 2010.

[11]C. Parthiban and N. Sundaramurthy, "Biosynthesis, characterization of $\mathrm{ZnO}$ nanoparticles by using pyrus pyrifolia leaf extract and their photocatalytic activity", International journal of innovative research in science, engineering and technology, vol. 4(10), pp. 9710-9718, 2015.

[12] L. Tian, Y. Rui, K. Sun, W. Cui and W. An, "Surface decoration of $\mathrm{ZnWO}_{4}$ nanorods with $\mathrm{Cu}_{2} \mathrm{O}$ nanoparticles to build heterostructure with enhanced photocatalysis", Nanomaterials, vol. 8(33), 2018.

[13] M. Aminuzzaman, L. P. Ying, W. Goh and A. Watanabe, "Green synthesis of zinc oxide nanoparticles using aqueous extract of Garcinia mangostana fruit pericarp and their photocatalytic activity", Bull. Mater. Sci., vol. $41,2018$.
[14] N. Ali, "In Vitro studies of antimicrobial activity of (curcuma longa 1.) rhizomes against helicobacter pylori”, Iraq Medical Journal, vol. 1(1), pp. 7-9, 2017.

[15]R. Sundaram and K. Maniraj, "Novel Nonstoichiometric Manganese-Cobalt-Nickel-Oxide composite as humidity sensor through solid-state electrical conductivity measurements", Sensors \& Transducers journal, vol. 70(8), pp. 671-678, 2006.

[16]D. He, L. Wang, D. Xu, J. Zhai, D. Wang and T. $\mathrm{Xie}$, "Investigation of photocatalytic activities over $\mathrm{Bi}_{2} \mathrm{WO}_{6} / \mathrm{ZnWO}_{4}$ composite under UV light and its photoinduced charge transfer properties", ACS Applied materials \& interfaces, vol. 3, pp. 3167-3171, 2011.

[17]M. Zhang, S. Wei, W. Ren and R. Wu, "Development of high sensitivity humidity sensor based gray $\mathrm{Tio}_{2} / \mathrm{SrTio}_{3}$ composite", Sensors, vol. 17, 2017.

[18] S. S. N. Fernando, T. D. C. P. Gunasekara and J. Holton, "Antimicrobial nanoparticles: applications and mechanism of action", Sri Lankan Journal of infectious diseases, vol. 8(1), pp. 2-11, 2018.

[19] I. A. P. Farias, C. C. L. D. Santos and F. C. Sampaio, "Antimicrobial activity of cerium oxide nanoparticles on opportunistic microorganisms: A systematic review", Biomed Research international, Vol. 2018, 2018.

[20]E. S. Araujo, V. N. S. Leao, S. R. Monteiro, R. P. Guimaraes, A. F. R. Barbosa and M. M. Nascimento, "Preparation of ceramic humidity sensors by electrospinning and sintering: a promising alternative", Research \& development in material science, vol. 6(5), 2018.

[21] A. Alhadhrami, A. S. A. Almaki, A. M. A. Adam and M. S. Refat, "Preparation of semiconductor zinc oxide nanoparticles as a photocatalyst to get rid of organic dyes existing factories in exchange for reuse in suitable purpose", International Journal of electrochemical Science, vol. 13, pp. 6503-6521, 2018.

[22] G. Huang and Y. Zhu, "Enhanced photocatalytic activity of $\mathrm{ZnWO}_{4}$ catalyst via fluorine doping", Journal of Physical Chemistry C, vol. 111, pp. 11952-11958, 2007.

[23]X. Zhao and Y. Zhu, "Synergetic degradation of Rhodamine $\mathrm{B}$ at a porous $\mathrm{ZnWO}_{4}$ film electrode by combined electro-oxidation and photocatalysis", Environmental Science \& Technology, vol. 40, pp. 3367-3372, 2006. 